\title{
Implicit learning modulates selective attention at sensory levels of perceptual processing
}

\author{
JANE W. COUPERUS \\ Hampshire College, Amherst, Massachusetts
}

\begin{abstract}
Electrophysiological evidence suggests that attention can be modulated as early as $100 \mathrm{msec}$ after stimulus presentation. However, it is not clear whether these changes are based primarily on stimulus properties such as perceptual load (i.e., the level of perceptual difficulty), or other properties, such as general attentional set or learned expectations concerning perceptual load. Using event-related potentials, this study examined how implicit learning of perceptual load conditions modulates selective attention at sensory levels of perceptual analysis. The results show significant differences in P1 amplitude recorded over occipital areas of the brain as a function of learned expectations of perceptual load, only when perceptual load could be reliably predicted by the preceding stimuli. Moreover, differences in processing were found when both low and high perceptual load conditions could be predicted. These findings suggest that implicit learning modulates the allocation of attention at early stages of perceptual processing.
\end{abstract}

Imagine an infant entering the world, bombarded by information. How does he or she focus attention to select out important information so as not to be overwhelmed by the vast amount that is available? Fortunately, humans have a valuable tool to help guide attention: implicit learning. Implicit learning is defined as the ability to learn without conscious awareness. Although research suggests that attention is modulated by implicit learning (see, e.g., Jiang \& Chun, 2001, 2003), it is not clear how early in processing this modulation occurs. Previous research suggests that attention can modulate processing of stimuli at sensory levels of analysis (for reviews, see Mangun, 1995, and Mangun \& Hillyard, 1995). Thus, it seems reasonable for one to suggest that implicit learning may indirectly act at this early stage of perceptual processing by modulating selective attention, making it easier to function in a stimulus-rich environment.

There are multiple theories that attempt to explain the mechanisms of early attentional selection (see, e.g., Broadbent, 1958; Lavie, 1995; Treisman \& Gelade, 1980); however, the specifics of attentional selection are still contested. For example, Lavie's perceptual load theory of selective attention (Lavie, 1995; Lavie, Hirst, de Fockert, \& Viding, 2004) implies that early attentional selection is influenced by perceptual features and the type of perceptual analysis required. Support for this idea can be found in electrophysiological studies that have shown changes in selective attention as a function of perceptual load as early as sensory-level processing in the extrastriate cortex (Handy \& Mangun, 2000; Handy, Soltani, \& Mangun, 2001). For example, when presented with a difficult perceptual discrimination (i.e., high perceptual load), at- tention is more narrowly focused, reducing the processing of a parafoveal distractor (Handy et al., 2001). This description of the narrowing of attention can be understood as a spotlight or a zoom lens (Posner \& Petersen, 1990), whereby attention is more diffuse under conditions of low perceptual load than of high perceptual load. Theeuwes, Kramer, and Belopolsky (2004) refined and extended this claim, suggesting that perceptual load alone is not sufficient for early attentional selectivity. They demonstrated that selective attention was most efficient during high perceptual load conditions in a block of high-load stimuli or if the current high-load stimulus was preceded by another high-load stimulus. Selection was not efficient when a high-load stimulus was preceded by a low-load stimulus. Thus, early attentional selection may be modified by other factors in addition to perceptual load, at least in conditions of high perceptual load.

Despite the aforementioned research, questions remain concerning the mechanisms of early attentional selection. Thus, it is important that we explore potential factors that may influence this process. Handy et al. (2001) suggested that changes in selective attention that are found when perceptual load is held constant across trials "should be eliminated if load is randomly varied within blocks" (p. 218), since participants would not be able to anticipate perceptual load. One potential source of this anticipation is implicit learning. Unfortunately, the use of block designs in perceptual load studies of selective attention has a serious limitation (see, e.g., Handy \& Mangun, 2000; Handy et al., 2001). Block-design studies do not exclude the possibility that changes in early selective attention are a function of broader changes in attentional set rather

J.W. Couperus, jcouperus@hampshire.edu 
than proximal changes in expected perceptual load. As was noted previously, when high and low perceptual load trials are presented in the same block, it is the level of the perceptual load of the previous stimulus that determines the level of processing of the current stimulus (Theeuwes et al., 2004). However, we hypothesize that when information concerning perceptual load can be gained through implicit learning, this knowledge will indirectly alter early processing by biasing early attentional selection.

Previous research has shown that there is a bidirectional relationship between implicit learning and selective attention (see, e.g., Chun \& Nakayama, 2000; Jiménez \& Méndez, 1999; Lambert, 2003; Turk-Browne, Jungé, \& Scholl, 2005). What is important in the present article is that implicit learning can modify visual selective attention. For example, studies using a visual search task called the contextual cuing paradigm (e.g., Chun \& Jiang, 1998; Jiang \& Chun, 2003) have demonstrated that implicit learning of spatial relations can alter selective attention. In these tasks, participants are presented with a set of displays that contain repeating sets of spatial information that can be used to locate target stimuli. When participants implicitly learn the repeating spatial information, reaction times (RTs) to locate the target items improve. These RT improvements reflect a more efficient search, since attention is more effectively deployed on the basis of the implicitly learned spatial configurations and their relation to the target locations.

To examine the possibility that implicit learning can modify selective attention at early levels of visual processing, event-related potentials (ERPs) were recorded from adult participants to determine whether implicit learning about perceptual load dynamically alters early selective attention. ERPs have high temporal resolution, which is ideal for a study (such as the present one) that concerns the timing of activity in the brain (see Rugg \& Coles, 1995). Specifically, this study examined the P1, a positive component that occurs approximately $100 \mathrm{msec}$ after stimulus onset. Previous research suggests that the P1 reflects activity in visual processing areas located in the extrastriate cortex (e.g., Di Russo, Martinez, \& Hillyard, 2003; Heinze et al., 1994; Mangun, Hopfinger, Kussmaul, Fletcher, \& Heinze, 1997). Additionally, attention has been shown to modulate the amplitude of the P1 (Handy \& Mangun, 2000; Handy et al., 2001; Mangun \& Hillyard, 1991). These changes have been characterized as a change in the gain of neuronal responses to stimuli (Hillyard, Vogel, \& Luck, 1998). It is theorized that sensory gain changes result in an improvement in the signal-to-noise ratio of attended stimuli, thus increasing the discriminability of the neural responses. In contrast, those stimuli that do not fall within the "spotlight" of attention do not benefit from such changes in the sensory gain. Thus, ERPs to attended stimuli show an increase in the amplitude of the $\mathrm{P} 1$ rather than a change in the time course or patterning of neural activity, and do not result in alterations of the waveform. ${ }^{1}$ Therefore, if implicit learning can modulate early selective attention during initial stages of visuocortical analysis, these changes in selective attention should be seen in the P1 response. Moreover, P1 changes should align with nonconscious (i.e., implicit) expectations concerning perceptual load at fixation. Thus, if a stimulus of high perceptual load is implicitly anticipated, the attentional focus should narrow, and the processing of a stimulus within the useful field of view ${ }^{2}$ should be reduced in comparison with when a stimulus of low perceptual load is implicitly anticipated. Moreover, no differences in processing between high- and low-load stimuli should be found if perceptual load cannot be anticipated on the basis of implicitly learned task parameters.

The goal of this study was to measure sensory-evoked ERP responses to task-irrelevant stimuli in the useful field of view under conditions in which (1) implicit learning of the perceptual load of foveal targets allows for the modulation of selective attention from trial to trial, and (2) no implicit learning is possible; thus, no modulation of selective attention from trial to trial on the basis of implicit learning is possible. To create the ability to anticipate perceptual load conditions, the target stimuli appeared in either a sequenced or random order in an implicit learning paradigm. Within each of these conditions, participants discriminated a target letter at either high or low load, using a design similar to that used by Handy and Mangun (2000). Finally, a task-irrelevant probe was presented on a subset of the trials so that changes in attentional focus as a result of expectations concerning perceptual load (based on implicit learning) could be inferred from the processing of an irrelevant stimulus in the useful field of view. Thus, we examined the effects of perceptual load on task-irrelevant processing under conditions in which perceptual load could be anticipated on the basis of implicit learning or could not be anticipated across trials.

\section{METHOD}

\section{Participants}

Twenty-eight adult participants (mean age $=19.89, S D=2.13$ ) participated in this study. Participants were recruited from local colleges (Hampshire, Amherst, Smith, and Mount Holyoke Colleges, as well as the University of Massachusetts at Amherst) and were paid $\$ 10$ for their participation. Thirteen males and 15 females participated. Participants were excluded from the analysis if they were left-handed, had noncorrectable visual impairments, were diagnosed with or suspected of having learning disorders, were currently on psychotropic medications, or were born premature (i.e., less than 36 weeks). Additionally, following initial EEG data reduction, participants were excluded if there were insufficient data for analysis (see Data Analysis and Reduction). Three participants were excluded on the basis of exclusionary criteria prior to data analysis (which were based on questionnaire data concerning medical history), and 3 were excluded during EEG data analysis and reduction due to insufficient data; thus, data from 22 participants were used in data analysis.

\section{Procedure}

After completing the consent process, all participants completed questionnaires addressing demographic information as well as a brief psychological and medical history.

\section{Modified Perceptual Load Task}

The paradigm was based on a design used by Handy and Mangun (2000). On each task trial, a small fixation was presented for $200 \mathrm{msec}$, followed by 1 of 10 letters (approximately $4.3^{\circ} \times 3.6^{\circ} \mathrm{vi}-$ 
sual angle), including 5 vowels (A, E, O, I, and $\mathrm{U}$ ) and 5 consonants (C, F, R, T, and M) (see Figures 1 and 2). Letters were presented at either low or high perceptual load, and participants were asked to identify the letter as a vowel or consonant using a buttonpress. In the low-load condition, the letter was presented for $100 \mathrm{msec}$ following fixation. In the high-load condition, the letter was presented for a shorter duration $(50,40$, or $30 \mathrm{msec})$ and was immediately followed by a patterned mask (a \# sign; onset coincided with the offset of the target). The sum of the duration of the letter and mask was $100 \mathrm{msec}$, and the ratio of the duration of the target to the mask was varied across epochs to maintain task difficulty. Half of the letters were assigned to the low-load condition, and the other half were assigned to the high-load condition, with the vowels and consonants split between conditions. The assignment of perceptual load to letters remained constant throughout the experiment, confounding load with letter. This was done because there were only two potential levels of perceptual load. Thus, the probabilistic relation between 2 adjacent trials on the basis of perceptual load alone was .50, which may be too low to motivate learning. However, the probabilistic relation between 2 adjacent trials during random sequences of 10 letters was as low as .10 at the beginning of a sequence, with an average probability of .25 across 10 letters. Thus, the benefit of sequence learning was greater for letters and might facilitate implicit learning during sequenced blocks. One confound induced by this pairing was that the pairing of load and letter could make the task easier, since participants learned to anticipate letters within the sequence rather than with the perceptual load, thus reducing the need to modulate attentional focus. However, rather than increasing significant findings, this would reduce the significance of any findings, reducing support for our hypotheses. Therefore, given the potential benefits for learning, perceptual load and stimulus letter were paired for this task. Trials were presented in blocks of 10 , and blocks were of two types: random and sequenced, similar to those used in a nonspatial serial RT task (see Stadler \& Frensch, 1998, for a review of other types of serial RT tasks). Each block type-sequenced and random - consisted of both high and low perceptual load letters. The only constraints were that each letter appear only once in each block, and no letter could be presented twice consecutively (e.g., the letter "A" at the end of a block could not be followed by " $A$ " at the beginning of the next block). Additionally, one 10-letter sequence was used for all sequenced blocks (see Figure 1). Thus, although sequenced and random trials were grouped in blocks, perceptual load varied trial by trial, avoiding the confound appearing in prior studies that blocked perceptual load conditions. This design created four stimulus conditions: sequenced block low perceptual load, sequenced-block high perceptual load, random-block low perceptual load, and random-block high perceptual load. Blocks alternated between random and sequenced across each epoch of 20 blocks. Three epochs were presented, for a total of 600 trials.

In addition, $20 \%$ of trials ( 30 total trials in each condition) were replaced by a probe trial that consisted of a fixation and irrelevant stimulus $\left(\mathrm{a} \%\right.$ symbol approximately $\left.4.3^{\circ} \times 3.6^{\circ}\right)$ that was presented

\begin{tabular}{|c|c|c|c|c|}
\hline Trial Number & Block Type & Perceptual Load & Stimulus & Probe Stimulus \\
\hline 1 & \multirow[t]{10}{*}{ Sequenced } & Low & $\mathrm{R}$ & \\
\hline 2 & & High & I & \\
\hline 3 & & Low & $\mathrm{U}$ & \\
\hline 4 & & High & $\mathrm{M}$ & $\%$ \\
\hline 5 & & High & $\mathrm{O}$ & \\
\hline 6 & & High & $\mathrm{A}$ & \\
\hline 7 & & Low & $\mathrm{C}$ & \\
\hline 8 & & Low & $\mathrm{E}$ & $\%$ \\
\hline 9 & & High & $\mathrm{F}$ & \\
\hline 10 & & Low & $\mathrm{T}$ & \\
\hline 11 & \multirow[t]{10}{*}{ Random } & High & $\mathrm{M}$ & \\
\hline 12 & & Low & $\mathrm{R}$ & \\
\hline 13 & & High & $\mathrm{O}$ & \\
\hline 14 & & High & $\mathrm{I}$ & \\
\hline 15 & & Low & $\mathrm{C}$ & \\
\hline 16 & & Low & $\mathrm{U}$ & $\%$ \\
\hline 17 & & Low & $\mathrm{T}$ & \\
\hline 18 & & High & $\mathrm{A}$ & $\%$ \\
\hline 19 & & Low & $\mathrm{E}$ & \\
\hline 20 & & High & $\mathrm{F}$ & \\
\hline 21 & \multirow[t]{10}{*}{ Sequenced } & Low & $\mathrm{R}$ & \\
\hline 22 & & High & I & \\
\hline 23 & & Low & $\mathrm{U}$ & $\%$ \\
\hline 24 & & High & M & \\
\hline 25 & & High & $\mathrm{O}$ & \\
\hline 26 & & High & $\mathrm{A}$ & \\
\hline 27 & & Low & $\mathrm{C}$ & \\
\hline 28 & & Low & $\mathrm{E}$ & $\%$ \\
\hline 29 & & High & $\mathrm{F}$ & \\
\hline 30 & & Low & $\mathrm{T}$ & \\
\hline 31 & \multirow[t]{4}{*}{ Random } & High & I & \\
\hline 32 & & Low & $\mathrm{C}$ & \\
\hline 33 & & Low & $\mathrm{U}$ & \\
\hline 34 & & High & $\mathrm{A}$ & $\%$ \\
\hline
\end{tabular}

Figure 1. Example epochs. Epochs consisted of 20 interleaved blocks (10 sequenced, 10 random). Twenty percent of trials were randomly replaced with probe trials. Gray lettering indicates that the stimulus was not presented since it was replaced by a probe trial. 
for $100 \mathrm{msec}$ at the top of the computer screen within the useful field of view (approximately $11.4^{\circ}$ above the foveal target). These targetfree trials allowed the measurement of stimulation within the useful field of view as a function of perceptual load, without confounding foveal stimulation. Probes were placed randomly, with the constraint that no 2 probe trials could be placed consecutively or replace the first or second letter of a sequenced block. Participants were asked to remain looking at the fixation during probe trials, and no response was required for probe trials.

Manual responses were recorded with a two-button mouse. Trials consisted of a 200-msec fixation, followed by the appearance of the letter-or letter and mask - for $100 \mathrm{msec}$ (see Figure 2). Participants were then presented with a fixation and given $4,000 \mathrm{msec}$ to respond. The response ended the trial and was followed by a random intertrial interval (ITI; range $=800-1,000 \mathrm{msec}$ ). Probe trials followed the same timing (fixation for $200 \mathrm{msec}$, probe for $100 \mathrm{msec}$ ); however, instead of being given $4,000 \mathrm{msec}$ to respond, because no response was required, a fixation appeared for $1,000 \mathrm{msec}$, followed by a random ITI (range $=800-1,000 \mathrm{msec}$ ).

After completing the modified perceptual load task, participants completed a questionnaire regarding potential explicit learning of the sequence. Participants were asked questions regarding the sequence and were given distractor questions to detect positive endorsement biases. Sequence questions included (1) whether they noticed a sequence, (2) what the letters of the sequence were, and (3) how confident they were of the sequence. Distractor questions included (a) whether they noticed if a particular letter appeared before the probe trials, (b) what the letter before probe trials was, and (c) how confident they were in seeing this combination of letter and probe trials. Of the 20 participants, 5 indicated some knowledge of the sequence. However, of these 5,3 indicated they were $25 \%$ or less sure that there was a sequence, ${ }^{3}$ and only 1 of the 5 was able to correctly indicate at least three letters of the sequence. ${ }^{4}$ Additionally, 2 of the 5 positively endorsed the correlation of a particular letter with the probe trial, suggesting a possible positive endorsement bias.
Electrophysiological methods. Scalp electroencephalograms (EEGs) were recorded with a 32-channel tin Electro-cap. Electrodes were referenced to linked mastoids, and impedances were kept below $5 \mathrm{k} \Omega$ for all participants. The mastoid reference is preferred with a smaller number of channels since the average reference is not as accurate with this number of electrodes (Handy, 2004). Data were recorded using a Synamps I amplifier with Scan 4.2 software, and they were digitized at the rate of $500 \mathrm{~Hz}$ using a bandpass filter of .1 to $30 \mathrm{~Hz}$. To ensure eye fixation, the electrooculogram (EOG) was recorded for both vertical (from an electrode inferior to the left eye) and horizontal (from an electrode on the right outer canthus) eye movements.

Data analysis and reduction. EEGs were epoched offline to examine event-related electrophysiological activity for all trials (200-msec prestimulus to $600-\mathrm{msec}$ poststimulus), and they were baseline corrected using a baseline of 200 -msec prestimulus. Trials were eliminated if there were significant eye artifacts (defined as amplitudes $\pm 50 \mu \mathrm{V}$ at vertical or horizontal eye electrodes) or if there was significant alpha activity in more than three channels (i.e., $10 \%$ ). Channels that were consistently bad across the experiment were marked as such and were not used in analyses. To ensure that all trials with artifacts were eliminated, each trial was also visually reviewed. Participants were eliminated from analyses if there were more than three bad channels (Picton et al., 2000) or if they had fewer than 20 artifact-free trials in any of the analyzed conditions. The resulting ERPs were used to produce grand-average waveforms for each participant for each of the four conditions used in statistical analysis: sequenced-block low perceptual load (probes that replaced low perceptual load letters within a sequenced block), sequencedblock high perceptual load (probes that replaced high perceptual load letters within a sequenced block), random-block low perceptual load (probes that followed a low perceptual load letter within a random sequence), and random-block high perceptual load (probes that followed a high perceptual load letter within a random sequence). Probes were divided into two conditions within random sequences

\section{Low Perceptual Load Trial}

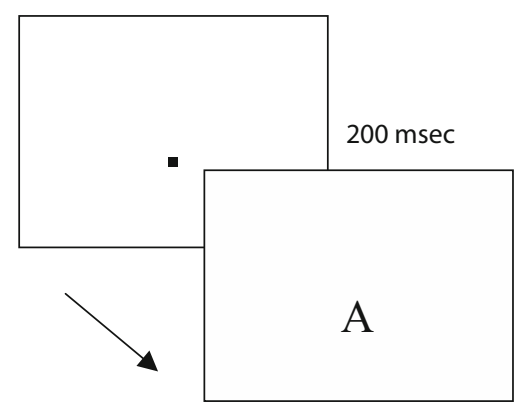

Probe Trial

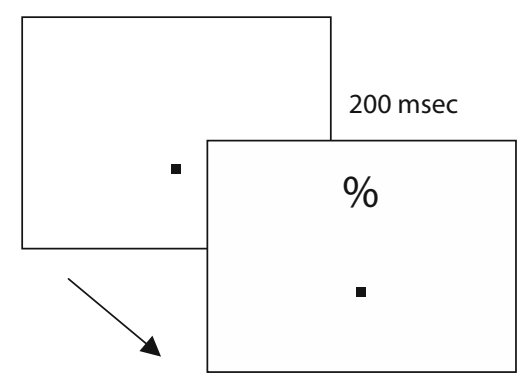

High Perceptual Load Trial

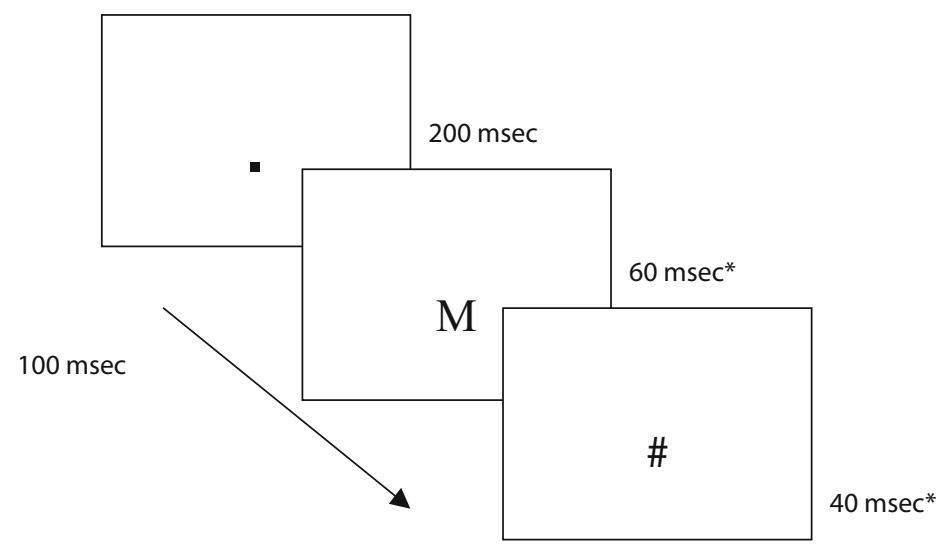

$100 \mathrm{msec}$
${ }^{*}$ Times reflect ratio in epoch 1 ; epoch 2 and 3 stimuli
were presented at 50/50 and 40/60, respectively.

Figure 2. Stimulus displays were presented in three types of trials, as shown above. 
Table 1

Accuracy and Reaction Times (RTs)

\begin{tabular}{|c|c|c|c|c|c|c|c|c|c|c|c|c|}
\hline & \multicolumn{4}{|c|}{ Epoch 1} & \multicolumn{4}{|c|}{ Epoch 2} & \multicolumn{4}{|c|}{ Epoch 3} \\
\hline & \multicolumn{2}{|c|}{$\begin{array}{l}\text { Sequenced } \\
\text { Blocks }\end{array}$} & \multicolumn{2}{|c|}{$\begin{array}{c}\text { Random } \\
\text { Blocks }\end{array}$} & \multicolumn{2}{|c|}{$\begin{array}{l}\text { Sequenced } \\
\text { Blocks } \\
\end{array}$} & \multicolumn{2}{|c|}{$\begin{array}{c}\text { Random } \\
\text { Blocks }\end{array}$} & \multicolumn{2}{|c|}{$\begin{array}{l}\text { Sequenced } \\
\text { Blocks } \\
\end{array}$} & \multicolumn{2}{|c|}{$\begin{array}{c}\text { Random } \\
\text { Blocks }\end{array}$} \\
\hline & $M$ & $S D$ & $M$ & $S D$ & $M$ & $S D$ & $M$ & $S D$ & $M$ & $S D$ & $M$ & $S D$ \\
\hline \multicolumn{13}{|c|}{ Accuracy ( $\%$ correct $)$} \\
\hline Low load & 96.3 & 3.4 & 93.7 & 4.0 & 96.7 & 3.6 & 96.3 & 2.9 & 95.9 & 4.1 & 2.6 & 5.1 \\
\hline High load & 63.1 & 12.5 & 68.7 & 13.0 & 70.8 & 11.3 & 80.1 & 6.9 & 61.4 & 15.3 & 74.9 & 10.4 \\
\hline \multicolumn{13}{|c|}{ RTs (in milliseconds) } \\
\hline Low load & 618.0 & 92.6 & 613.1 & 92.7 & 577.9 & 79.2 & 576.7 & 71.9 & 547.1 & 74.7 & 560.5 & 83.7 \\
\hline High load & 713.2 & 112.9 & 678.7 & 117.7 & 647.1 & 114.1 & 624.8 & 119.4 & 619.9 & 110.4 & 610.0 & 112.0 \\
\hline
\end{tabular}

to examine potential carryover effects that might contribute to the processing of the probe stimulus. Thus, the baseline comparison for probes replacing low perceptual load letters in a sequence were probes following a low perceptual load letter in a random sequence (with the opposite scenario for high perceptual load conditions). ${ }^{5}$ Statistical analysis of $\mathrm{P} 1$ data was based on average amplitude measured over a 50-msec time window, centered approximately on the peak amplitude of the P1 seen in the grand-averaged waveforms of the occipital leads O1, OZ, and O2 (110-160 msec poststimulus). Data from the three occipital leads were then averaged to generate a dependent variable to be used in analyses. However, analyses on individual electrodes were performed, and they showed similar significance in all occipital leads. Data were analyzed using a 2 (sequence type) $\times 2$ (perceptual load) ANOVA on P1 amplitude to probe stimuli using a Greenhouse-Geisser correction to be consistent with the broader ERP literature. Data from 22 participants were included in analysis, with an average of 23.51 trials per condition $(S D=1.71)$. Although not a focus of this study, data were analyzed for the N1, and significant findings were consistent with results found at P1. ${ }^{6}$ Differences in processing at N1 may reflect a gain-control change in early processing due to selective attention, as has been suggested by previous research (for a review, see Hillyard et al., 1998). Of interest for future studies is the nature of the relation between $\mathrm{P} 1$ and $\mathrm{N} 1$ and how they may reflect similar and/or different processes. However, since N1 data provide little additional information in the context of this study, and since it is the earliest changes in visual processing that are the primary focus of this study, data from $\mathrm{N} 1$ are not presented. Additionally, since this study focused on early perceptual processing, data from the $\mathrm{P} 2$ and $\mathrm{P} 3$ are not presented.

\section{RESULTS}

\section{Statistical Analyses}

Behavioral analysis. Prior to analysis, responses that were less than $300 \mathrm{msec}$ (i.e., anticipations or responses to previous stimuli, resulting in an average loss of under $2 \%$ of data) or greater than $3 S D$ s above the mean were eliminated. Additionally, only correct responses were used for RT data, and data were reduced by creating means for each epoch for both accuracy (percentage correct) and RT. Two 2 (perceptual load) $\times 2$ (sequence type) $\times 3$ (epoch) repeated measures ANOVAs were conducted.

As anticipated, a main effect of perceptual load indicated that accuracy for high perceptual load stimuli was lower than that for low-load stimuli $[M \mathrm{~s}=70 \%$ and $94 \%$, respectively; $\left.F(1,21)=119.50, p<.001, \eta_{\mathrm{p}}^{2}=.85\right]$. Additionally, accuracy decreased slightly overall across epochs $\left[F(2,42)=36.75, p<.001, \eta_{\mathrm{p}}^{2}=.64\right]$ and was slightly lower for random than for sequenced letters overall $\left[F(1,21)=9.83, p=.005, \eta_{\mathrm{p}}^{2}=.32\right]($ see Table 1$)$.
There were two-way interactions between epoch and sequence type $\left[F(2,42)=7.08, p=.003, \eta_{\mathrm{p}}^{2}=.25\right]$, between epoch and perceptual load $[F(2,42)=14.47$, $\left.p<.001, \eta_{\mathrm{p}}^{2}=.41\right]$, and between perceptual load and sequence type $\left[F(1,21)=159.17, p<.001, \eta_{\mathrm{p}}^{2}=.88\right]$. Finally, a three-way interaction was found between epoch, perceptual load, and sequence type $[F(2,42)=44.20, p<$ $\left..001, \eta_{\mathrm{p}}^{2}=.68\right]$.

RT data show that participants were slower to respond to letters presented at high perceptual load than to those presented at low perceptual load $[F(1,21)=44.28, p<$ $\left..001, \eta_{\mathrm{p}}^{2}=.68\right]$. Additionally, RTs improved across epochs for all stimuli $\left[F(2,42)=23.43, p<.001, \eta_{\mathrm{p}}^{2}=.53\right]$, reflecting practice effects. However, of greater importance for the hypotheses in this study, a significant main effect of sequence (suggesting faster responses for sequenced than for random letters) $\left[F(1,21)=7.33, p=.013, \eta_{\mathrm{p}}^{2}=.26\right]$, combined with a significant interaction between sequence type and epoch $\left[F(2,42)=4.16, p=.023, \eta_{\mathrm{p}}^{2}=.17\right]$, demonstrate implicit learning of letters within a sequence (see Figure 3). Additionally, there were significant interactions between perceptual load and epoch $[F(2,42)=$ $\left.4.39, p=.021, \eta_{\mathrm{p}}^{2}=.17\right]$ and between sequence type and perceptual load $\left[F(1,21)=12.13, p=.002, \eta_{\mathrm{p}}^{2}=.36\right]$. Follow-up $t$ tests at the final epoch confirmed that there were significant differences in the RT between sequenced low-load letters and random low-load letters $[t(21)=$ $-2.39, p=.026]$ but not between sequenced high and random high letters $[t(21)=.861, p=.39]$. These effects reflect decreased RTs for low perceptual load letters within a sequence as compared with randomly presented letters across epochs, with no analogous effect for high perceptual load letters (see Table 1 for mean RTs). Learning effects in the high-load condition may have been obscured due to increasing difficulty of high perceptual load letters across epochs. This was done to maintain task difficulty of the high-load condition across epochs. However, the pattern of RTs for low perceptual load letters suggests implicit learning of the sequence of letters, at least at low perceptual load.

Electrophysiological analyses. Consistent with behavioral findings, a 2 (sequence type) $\times 2$ (perceptual load) ANOVA on P1 amplitude to probe stimuli showed a significant interaction between sequence type and perceptual load $\left[F(1,21)=10.78, p=.004, \eta_{\mathrm{p}}^{2}=.34\right]$. This interaction suggests that implicit learning of the sequenced 


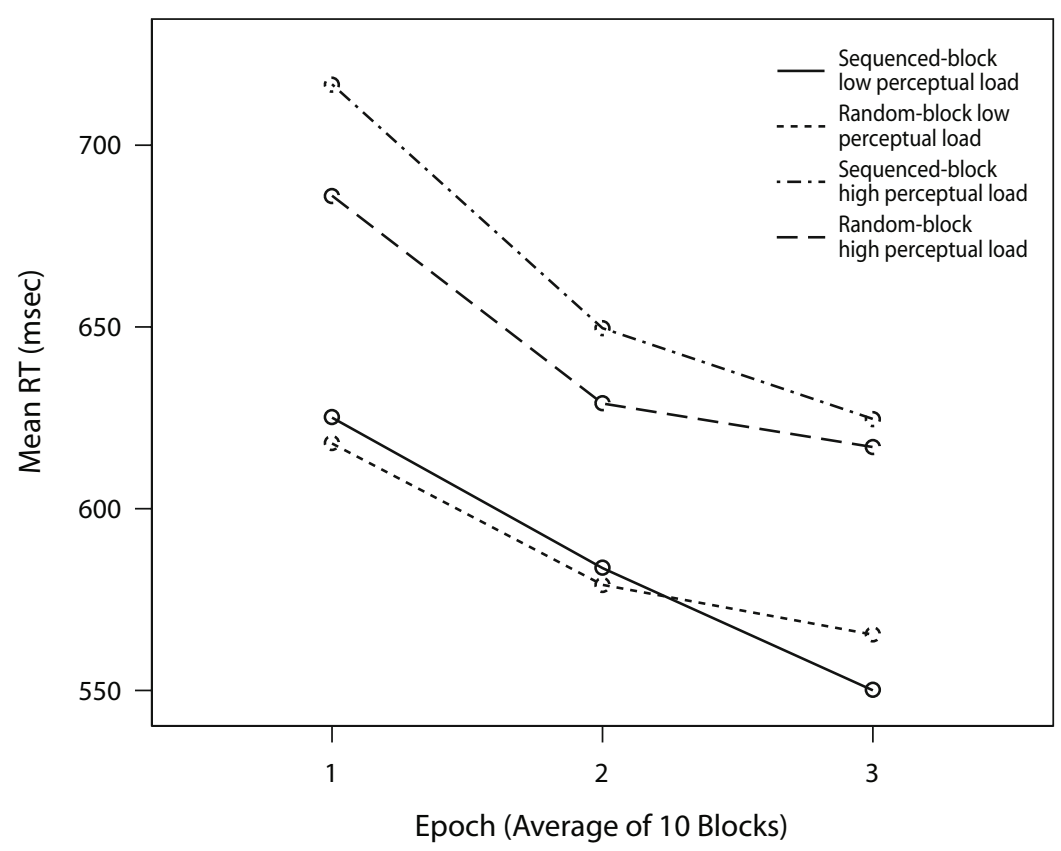

Figure 3. Mean reaction times (RTs). Mean RTs for sequenced and unsequenced blocks at high or low perceptual load across three epochs. Each epoch represents the average across 10 blocks.

letters influences processing of the task-irrelevant distractor as a function of anticipated perceptual load at fovea (see Figures 4 and 5). To test a priori hypotheses, four $t$ tests were performed. As anticipated, P1 amplitude was greater for probes replacing low perceptual load letters in sequenced blocks than it was for probes following low perceptual load letters in random blocks $[t(21)=3.31$, $p=.003]$, and it was lower for probes replacing high perceptual load letters within sequenced blocks than it was for those following high perceptual load letters in random blocks $[t(21)=-2.16, p=.043]$. Additionally, the P1 showed reduced processing of task-irrelevant probes replacing sequenced letters at high perceptual load, as compared with task-irrelevant probes replacing sequenced letters at low perceptual load $[t(21)=3.55, p=.002]$. In contrast, there were no significant differences between task-irrelevant probes following random stimuli letters presented at high as opposed to low perceptual load $[t(21)=-1.21, p=.241]$.

\section{DISCUSSION}

This study examined the behavioral and neural effects of implicit learning on early perceptual processing by examining the effects of perceptual load under conditions when it could be anticipated as a function of implicit learning or could not be anticipated across trials. The results of this study support previous findings (Handy et al., 2001) that perceptual load at fixation modulates the processing of a parafoveal stimulus. Moreover, the results suggest that implicit learning can modulate attentional selection early in visuocortical processing and can account for changes in selective attention above and beyond the effects of percep- tual load. When a low perceptual load stimulus letter was replaced by a probe within an implicitly learned sequence of high and low perceptual load letters, the amplitude of the P1 response to the task-irrelevant probe stimulus was significantly greater than it was when it appeared within a random sequence. Additionally, when a high perceptual load stimulus letter could be anticipated as a function of implicit learning of the sequence, P1 amplitude to the task-irrelevant probe was significantly reduced, in comparison with a probe following a high perceptual load stimulus within a random sequence, and a probe replacing a low perceptual load letter within an implicitly learned sequence. In contrast, there were no significant differences between the processing of irrelevant probes following high- and low-load stimuli when the stimulus load could not be anticipated by the preceding stimulus (i.e., the probe was presented in a random sequence). This result supports the prediction by Handy et al. (2001) suggesting that when perceptual load cannot be predicted, no differences as a function of perceptual load should be seen. Additionally, results demonstrate that knowledge gained through implicit learning (in this case, knowledge of perceptual load) influences early sensory processing.

Peak differences in processing as a function of changes in early selective attention occurred approximately $140-150$ msec after stimulus onset, suggesting processing changes in extrastriate cortex (see, e.g., Heinze et al., 1994; Mangun et al., 1997). Since the present results were obtained on trials in which no task-relevant information was present, it is clear that perceptual or task demands are not responsible for differences in processing. Instead, implicitly learned expectations concerning perceptual load biased early selective attention (and, in turn, early sensory 

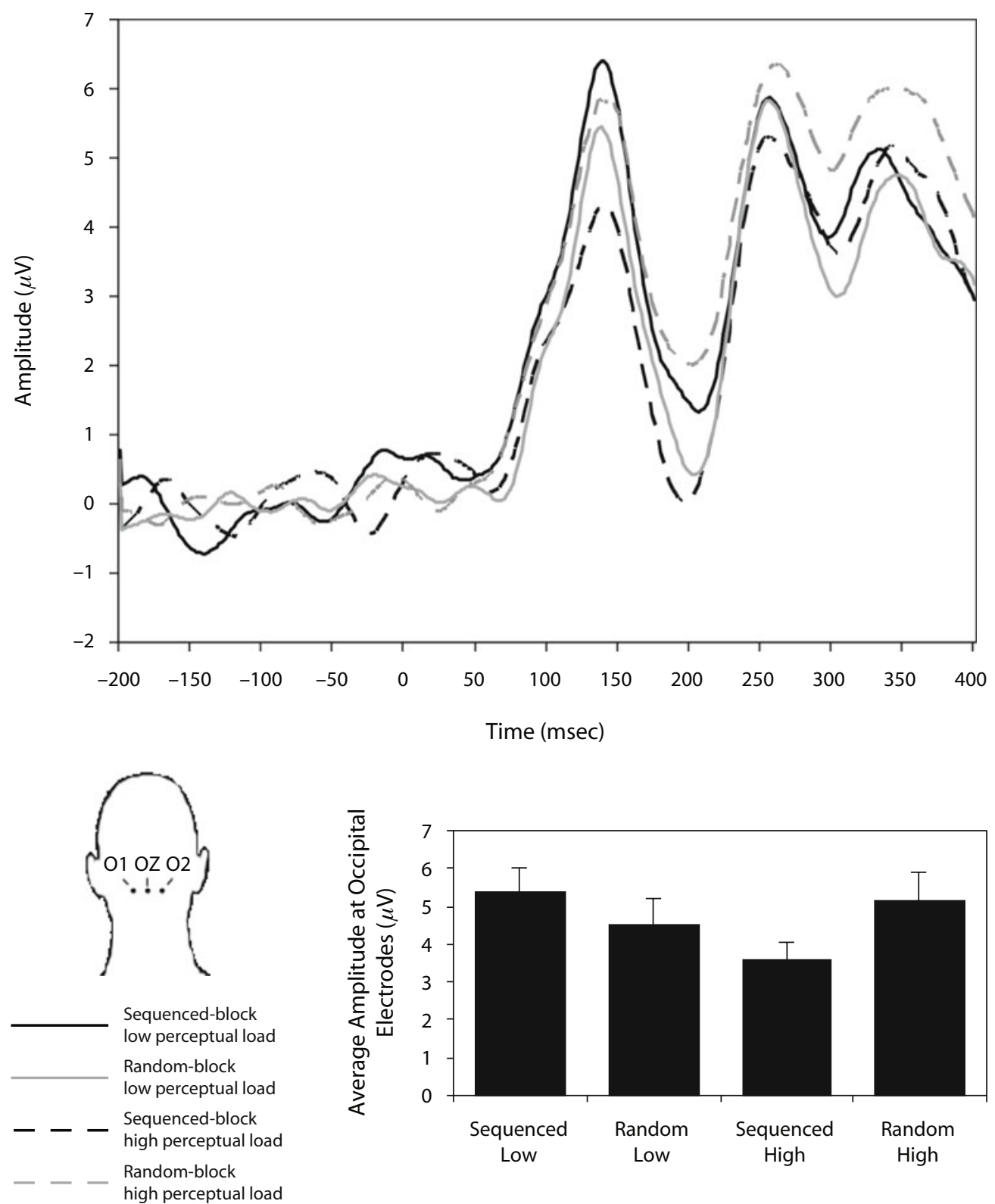

Figure 4. $\mathrm{P1}$ responses to the task-irrelevant probe averaged across three electrodes: $\mathrm{O1}, \mathrm{OZ}$, and $\mathrm{O} 2$.

processing) during sequenced blocks. Within the context of theories describing selective attention as a spotlight or zoom lens (Posner \& Petersen, 1990), the findings of the present study suggest that implicit learning of perceptual load conditions influences the distribution or extent of selective attention. When perceptual load of an upcoming stimulus can be anticipated through implicit learning, selective attention either narrows in anticipation of a high perceptual load stimulus or widens in anticipation of a low perceptual load stimulus, thus modifying early visuocortical processing. Moreover, the data are consistent with gain theories of selective attention (Hillyard et al., 1998) that suggest selective attention is the result of a change in the gain of the neurons underlying visual processing. In contrast, no significant differences were found in the pro- cessing of task-irrelevant probe stimuli during random sequences. Thus, it is not clear what factors influence early visuocortical processing when perceptual load cannot be implicitly predicted. Future studies should examine additional factors, such as general attentional set and expectations derived from proximal stimuli that may influence early attentional selection under these conditions. Moreover, future studies should explore responses to probes during sequenced trials on the basis of the perceptual load of the previous letter in the sequence in combination with the perceptual load of the anticipated letter, since-due to the small number of trials - it was not possible to examine this interaction in the present study.

There are several implications of this study for models of early selective attention, particularly for the model pre- 


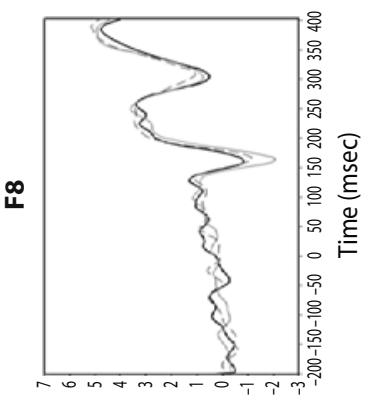

$\left(\wedge n^{\prime}\right)$ әрn!!|dur

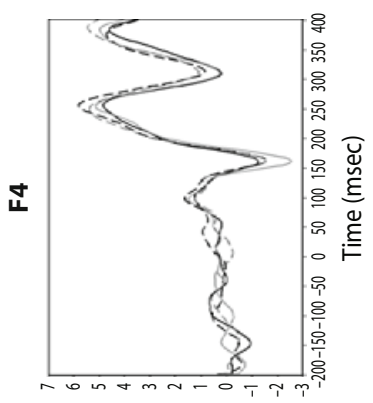

$\left(\wedge n^{\prime}\right)$ әрп!!!dur

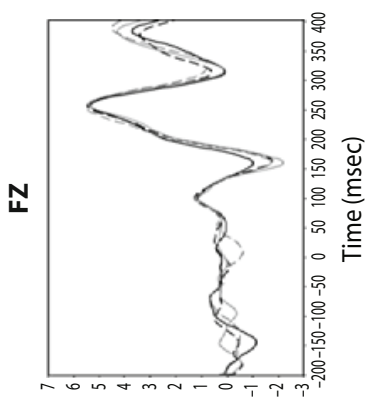

$\left(\wedge^{\prime}\right)$ әрn+!!dur

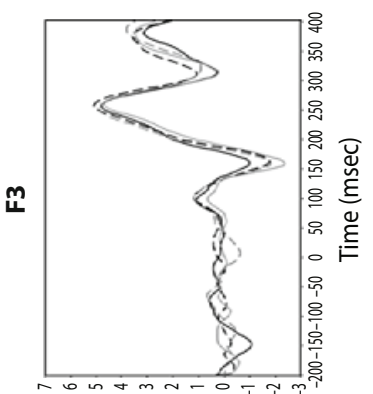

( $\left.n^{\prime}\right)$ әрпџ!|dur

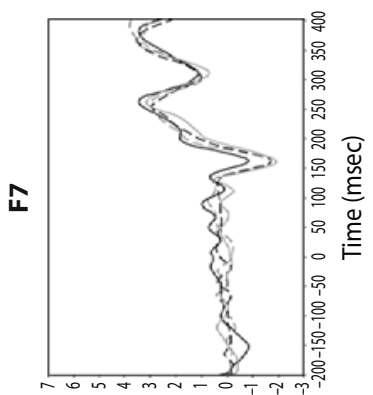

$\left(\wedge^{\prime}\right)$ әрп,!|dü

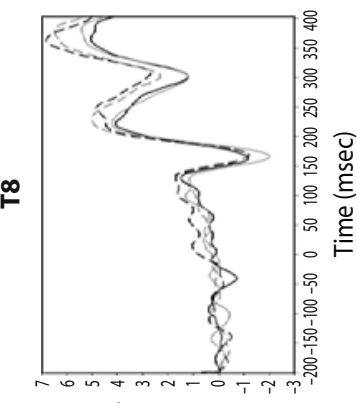

$\left(\wedge n^{\prime}\right)$ әрп?!!dur

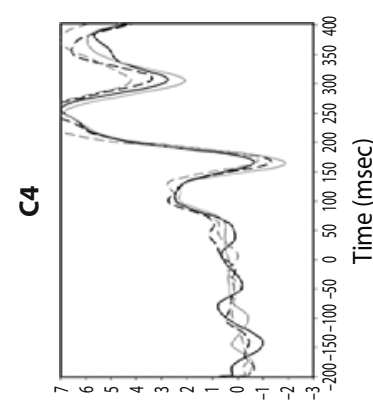

$\left(\wedge n^{\prime}\right)$ әрпџ!|dur

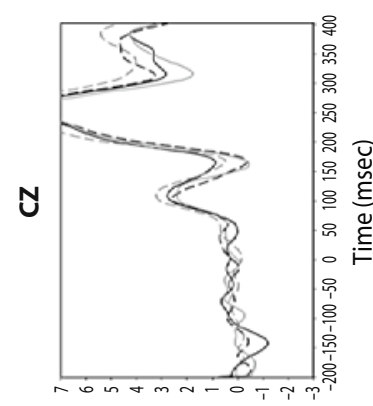

$\left(\wedge^{n}\right)$ әрпџ!!dur

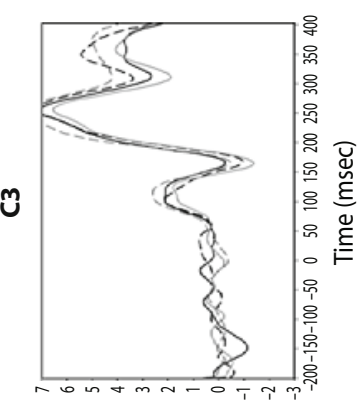

$\left(\wedge n^{\prime}\right)$ әрn+!|dur

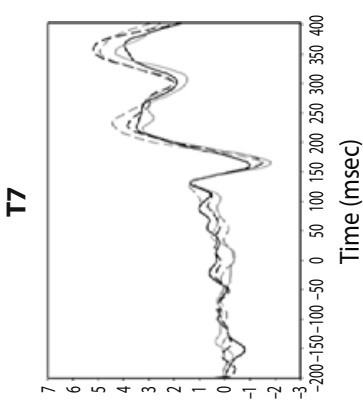

$\left(\wedge n^{\prime}\right)$ әрn+!|dur

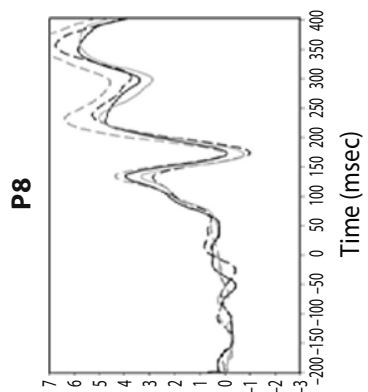

$\left(n^{\prime}\right)$ әрпч!!dur

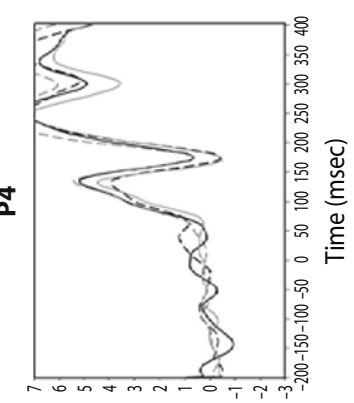

$\left(\wedge n^{\prime}\right)$ әрn!!!dur

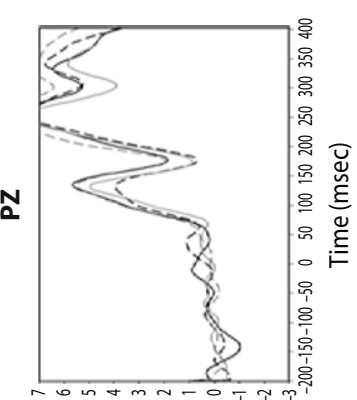

$\left(\wedge n^{\prime}\right)$ әрпч!!dur

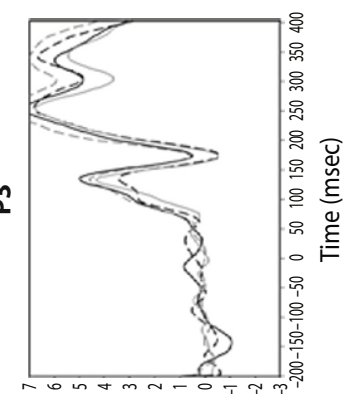

$\left(\wedge n^{\prime}\right)$ әрп?!!dur

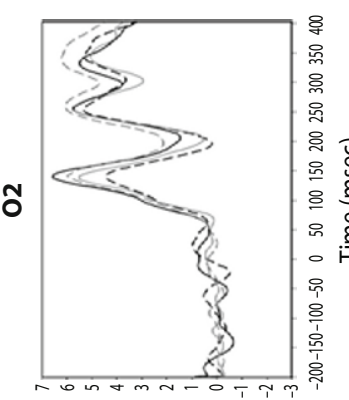

$\left(\wedge n^{\prime}\right)$ әрпџ!|dü

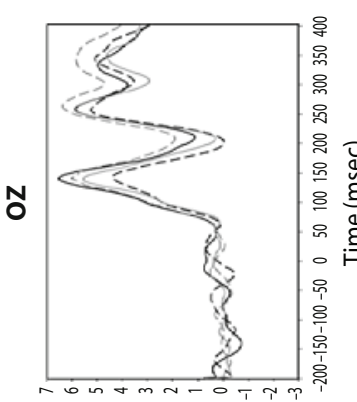

$\left(\wedge^{\prime}\right)$ әрп!!|dur

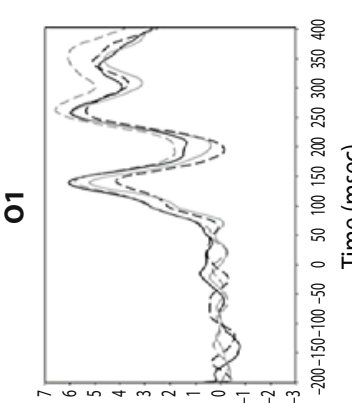

$\left(\wedge n^{\prime}\right)$ әpn!!!dur
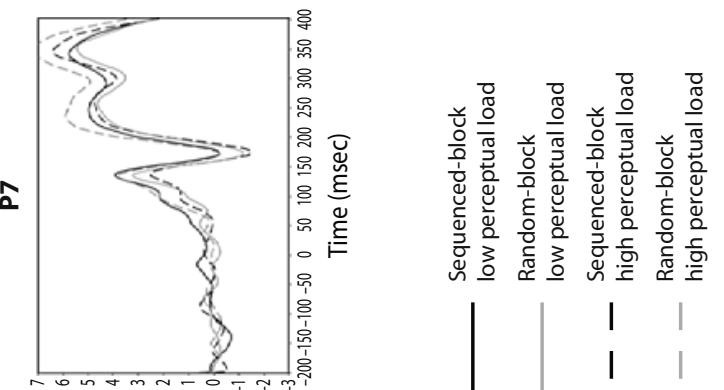

$\left(\wedge n^{\prime}\right)$ әpn!!|dur 
sented by Lavie (1995). First, Lavie claimed that perceptual load is a "major determinant of the processing of irrelevant distractors" (Lavie \& Cox, 1997, p. 398). However, consistent with that of Theeuwes and colleagues (2004), the present study demonstrates that perceptual load alone is not sufficient for determining early attention allocation. Second, findings support the proposal that learned expectations about perceptual load play an important modifying role in early selective attention (Handy et al., 2001). This is inconsistent with early selection models (see, e.g., Broadbent, 1958; Treisman \& Gelade, 1980) that place mechanisms of selection on stimulus properties and on the type of perceptual analysis required. Rather, it is likely that changes in early attentional selection found in this study are endogenous in nature. Finally, unlike Theeuwes and colleagues - who suggested that expectancies appear to play little role in low-load conditions, stating that "processing is driven in a bottom-up manner" (2004, p. 701)-we demonstrated that expectations of low perceptual load influenced the processing of task-irrelevant stimuli within the useful field of view. This may be due to differences within the methodology utilized, since Theeuwes et al. examined RTs during a behavioral task. Theeuwes et al. showed that under low-load conditions, processing of tobe-ignored stimuli occurred both when perceptual load could be anticipated (within a low perceptual load block) and when it could not (during a mixed block of high and low perceptual load trials). They did not find differences in the processing of the to-be-ignored stimuli in the lowload conditions. However, it is possible that RTs may not have been sensitive enough to see variations in processing of to-be-ignored items in low-load trials. These variations were seen in the present study, since there was a significant difference in the $\mathrm{P} 1$ between probes replacing low perceptual load letters within a nonrandom sequence as compared with those presented within a random sequence. Thus, the results of this study suggest that expectancies gained through implicit learning can affect early selective attention in both low and high perceptual load conditions.

One possible limitation of this study was that behavioral responses during the final epoch did not indicate implicit learning for high perceptual load letters. One possible reason for this lack of learning was the difficulty discriminating letters at high perceptual load (accuracy ranged from $60 \%$ to $80 \%$ ). Moreover, both the changing difficulty level between blocks for high perceptual load letters and the temporal interruption of the sequence with irrelevant probe letters could have interfered with the learning of the high perceptual load letters (see Stadler \& Frensch, 1998, for a discussion of factors that influence sequence learning). Importantly, however, for this study, full learning of the letters within sequences was not necessary for the learning of the sequence of perceptual load levels within a sequenced block (i.e., participants could potentially learn a sequence such as high load, low load, low load, high load, etc. without learning individual letters). Thus, it is possible that the learning of the low-load letters within a sequence was sufficient to facilitate the learning of the sequence of perceptual load. This possibility is supported by the ERP evidence, which clearly reflects implicit learning of the perceptual load of high perceptual load letters within a sequence, since early attentional processing for probes was significantly modulated in this condition. This finding is not unexpected; research suggests that behavioral performance is not always an indication of implicit learning (see, e.g., Frensch, Lin, \& Buchner, 1998; Frensch, Wenke, \& Ruenger, 1999; Jiang \& Leung, 2005).

In summary, this study provides evidence that attentional selection can be modified by implicit learning at early stages of perceptual processing. Consistent with Theeuwes et al. (2004), this study has shown that perceptual load alone is not sufficient for early selective attention, but, unlike their findings, this study suggests that early selective attention can modify processing under conditions of both low and high perceptual load.

\section{AUTHOR NOTE}

We thank Dr. Lisa Scott for her insightful feedback on the manuscript. This research was supported by the Keck Faculty Development Fund at Hampshire College. Address correspondence to J. W. Couperus, Hampshire College, Adele Simmons Hall, Cognitive Sciences, Amherst, MA 01002 (e-mail: jcouperus@hampshire.edu).

\section{REFERENCES}

Ball, K. K., Beard, B. L., Roenker, D. L., Miller, R. L., \& Griggs, D. S. (1988). Age and visual search: Expanding the useful field of view. Journal of the Optical Society of America A, 5, 2210-2219.

Broadbent, D. E. (1958). Perception and communication. Elmsford, NY: Pergamon. doi:10.1037/10037-000

Chun, M. M., \& Jiang, Y. (1998). Contextual cuing: Implicit learning and memory of visual context guides spatial attention. Cognitive Psychology, 36, 28-71. doi:10.1006/cogp.1998.0681

Chun, M. M., \& NaKayama, K. (2000). On the functional role of implicit visual memory for the adaptive deployment of attention across views. Visual Cognition, 7, 65-81. doi:10.1080/135062800394685

Di Russo, F., Martinez, A., \& Hillyard, S. A. (2003). Source analysis of event-related cortical activity during visual-spatial attention. Cerebral Cortex, 13, 486-499. doi:10.1093/cercor/13.5.486

Frensch, P. A., Lin, J., \& Buchner, A. (1998). Learning versus behavioral expression of the learned: The effects of a secondary tonecounting task on implicit learning in the serial reaction task. Psychological Research, 61, 83-98. doi:10.1007/s004260050015

Frensch, P. A., Wenke, D., \& Ruenger, D. (1999). A secondary tonecounting task suppresses expression of knowledge in the serial reaction task. Journal of Experimental Psychology: Learning, Memory, \& Cognition, 25, 260-274. doi:10.1037/0278-7393.25.1.260

HANDY, T. C. (2004). Event-related potentials: A methods handbook. Cambridge, MA: MIT Press.

Handy, T. C., \& Mangun, G. R. (2000). Attention and spatial selection: Electrophysiological evidence for modulation by perceptual load. Perception \& Psychophysics, 62, 175-186.

Handy, T. C., Soltani, M., \& Mangun, G. R. (2001). Perceptual load and visuocortical processing: Event-related potentials reveal sensorylevel selection. Psychological Science, 12, 213-218. doi:10.1111/1467 $-9280.00338$

Heinze, J. J., Mangun, G. R., Burchert, W., Hinrichs, H., Scholz, M., Münte, T. F., ET AL. (1994). Combined spatial and temporal imaging of brain activity during visual selective attention in humans. Nature, 372, 543-546. doi:10.1038/372543a0

Hillyard, S. A., Vogel, E. K., \& Luck, S. J. (1998). Sensory gain control (amplification) as a mechanism of selective attention: Electrophysiological and neuroimaging evidence. Philosophical Transactions of the Royal Society of London B, 353, 1257-1270.

JASPER, H. (1958). The ten-twenty electrode system of the International Federation. Electroencephalography \& Clinical Neurophysiology, 10, 371-375. 
JiANG, Y., \& ChUn, M. M. (2001). Selective attention modulates implicit learning. Quarterly Journal of Experimental Psychology, 54A, 1105 -1124. doi: $10.1080 / 02724980042000516$

JiAng, Y., \& Chun, M. M. (2003). Contextual cuing: Reciprocal influences between attention and implicit learning. In L. Jiménez (Ed.), Attention and implicit learning: Advances in consciousness (Vol. 48, pp. 277-296). Amsterdam: John Benjamins.

JIANG, Y., \& LEUNG, A. W. (2005). Implicit learning of ignored visual context. Psychonomic Bulletin \& Review, 12, 100-106.

JiMÉNEZ, L., \& MÉNDEZ, C. (1999). Which attention is needed for implicit sequence learning? Journal of Experimental Psychology: Learning, Memory, \& Cognition, 25, 236-259. doi:10.1037/0278-7393.25.1.236

LAMBERT, T. (2003). Visual orienting, learning and conscious awareness. In L. Jiménez (Ed.), Attention and implicit learning: Advances in consciousness (Vol. 48, pp. 253-275). Amsterdam: John Benjamins.

LAVIE, N. (1995). Perceptual load as a necessary condition for selective attention. Journal of Experimental Psychology: Human Perception \& Performance, 21, 451-468. doi:10.1037/0096-1523.21.3.451

Lavie, N., \& Cox, S. (1997). On the efficiency of visual selective attention: Efficient visual search leads to inefficient distractor rejection. Psychological Science, 8, 395-398. doi:10.1111/j.1467-9280.1997 .tb00432.X

Lavie, N., Hirst, A., de Fockert, J. W., \& Viding, E. (2004). Load theory of selective attention and cognitive control. Journal of Experimental Psychology: General, 133, 339-354. doi:10.1037/0096 $-3445.133 .3 .339$

Mangun, G. R. (1995). Neural mechanisms of visual selective attention. Psychophysiology, 32, 4-18. doi:10.1111/j.1469-8986.1995 .tb03400.x

Mangun, G. R., \& Hillyard, S. A. (1991). Modulations of sensoryevoked brain potentials indicate changes in perceptual processing during visual-spatial priming. Journal of Experimental Psychology: Human Perception \& Performance, 17, 1057-1074. doi:10.1037/0096 $-1523.17 .4 .1057$

Mangun, G. R., \& Hillyard, S. A. (1995). Mechanisms and models of selective attention. In M. D. Rugg \& M. G. H. Coles (Eds.), Electrophysiology of mind: Event-related brain potentials and cognition (pp. 40-85). New York: Oxford University Press.

Mangun, G. R., Hopfinger, J. B., Kussmaul, C. L., Fletcher, E., \& HeInZE, H. J. (1997). Covariations in ERP and PET measures of spatial selective attention in human extrastriate visual cortex. Human Brain Mapping, 5, 273-279. doi:10.1002/(SICI)10970193(1997)5:4<273::AID-HBM12>3.0.CO;2-F

Picton, T. W., Bentin, S., Berg, P., Donchin, E., Hillyard, S. A., JohnSON, R., JR., ET AL. (2000). Guidelines for using human eventrelated potentials to study cognition: Recording standards and publication criteria. Psychophysiology, 37, 127-152. doi:10.1017/ S0048577200000305

Posner, M. I., \& Petersen, S. E. (1990). The attention system of the human brain. Annual Review of Neuroscience, 13, 25-42. doi:10.1146/ annurev.ne.13.030190.000325

RugG, M. D., \& Coles, M. G. H. (1995). Electrophysiology of mind: Event-related brain potentials and cognition. New York: Oxford University Press.

Stadler, M. A., \& Frensch, P. A. (1998). Handbook of implicit learning. Thousand Oaks, CA: Sage.

Theeuwes, J., Kramer, A. F., \& Belopolsky, A. V. (2004). Attentional set interacts with perceptual load in visual search. Psychonomic Bulletin \& Review, 11, 697-702.
Treisman, A. M., \& Gelade, G. (1980). A feature integration theory of attention. Cognitive Psychology, 12, 97-136. doi:10.1016/0010 $-0285(80) 90005-5$

Turk-Browne, N. B., Jungé, J., \& Scholl, B. J. (2005). The automaticity of visual statistical learning. Journal of Experimental Psychology: General, 134, 552-654. doi:10.1037/0096-3445.134.4.552

WiLLIAMS, L. J. (1989). Foveal load affects the functional field of view. Human Performance, 2, 1-28. doi:10.1207/s15327043hup0201_1

\section{NOTES}

1. Changes in sensory processing as a function of a change in the gain of neurons can also be found at the N1. However, since the focus of this study was on the earliest changes in sensory processing, the N1 was not included in analysis or discussion.

2. Although previous studies (e.g., Handy \& Mangun, 2000) examined processing within the parafoveal region that encompasses an area approximately $5^{\circ}$ surrounding fixation (Williams, 1989), this study examined processing within the useful field of view (Ball, Beard, Roenker, Miller, \& Griggs, 1988) to increase effect sizes by utilizing areas of the visual field farther from fixation (approximately $11^{\circ}$ from fixation).

3. The 2 participants who indicated that they were more than $25 \%$ sure included 1 who was $100 \%$ sure of seeing a sequence; however, the participant indicated the presence of only two letters in sequence. The other indicated being $50 \%$ sure of seeing two or three letters in sequence; however, these letters did not actually appear in a sequence.

4. One participant noted a five-letter sequence; however, the sequence contained only three correct letters.

5. Although the data presented used the adjusted baseline described, additional analyses using a true baseline (consisting of probes replacing both low and high perceptual load letters within a random sequence) show similar findings. A significant main effect $[F(2,21)=7.28, p=$ $\left..004, \eta_{\mathrm{p}}^{2}=.257\right]$ of condition was found in a three-way ANOVA using a Greenhouse-Geisser correction. Additionally, follow-up $t$ tests showed a significant difference between probes replacing letters at low perceptual load within a sequence and probes within a random sequence $[t(21)=$ $2.13, p=.043]$, and between probes replacing high perceptual load letters within a sequence and probes within a random sequence $[t(21)=$ $-2.43, p=.039]$. Moreover, there was a significant difference between probes replacing high perceptual load letters within a sequence and low perceptual load letters within a sequence $[t(21)=3.55, p=.002]$.

6 . There was a significant interaction between sequence type and perceptual load at the $\mathrm{N} 1\left[F(1,21)=5.44, p=.030, \eta_{\mathrm{p}}^{2}=.21\right]$. Additionally, $t$ tests revealed significant differences between probes replacing sequenced letters at high perceptual load as compared with low perceptual load $[t(21)=-2.11, p=.047]$, and probes replacing sequenced letters at high perceptual load as compared with probes replacing letters in random sequences at high perceptual load $[t(21)=2.10, p=$ $.048]$. Unlike effects at $P 1$, there was not a significant difference between probes replacing sequenced letters at low perceptual load and those in random sequences $[t(21)=-1.63, p=.118]$, and there was a trend difference between letters in random sequences that were presented at high perceptual load as compared with low perceptual load $[t(21)=$ 2.03, $p=.055]$.

(Manuscript received March 18, 2008; revision accepted for publication August 21, 2008.) 